\title{
Improvement of Gas Drainage Efficiency via Optimization of Sealing Depth of Cross-Measure Boreholes
}

\author{
Pu Li, ${ }^{1,2}$ Zhiheng Cheng $\left(\mathbb{D},{ }^{3}\right.$ Liang Chen ${ }^{1},{ }^{3}$ Hongbing Wang, ${ }^{3}$ and Jialin $\mathrm{Cao}^{3}$ \\ ${ }^{1}$ School of Energy Science and Engineering, Henan Polytechnic University, Jiaozuo, Henan 454000, China \\ ${ }^{2}$ Zhengzhou Coal Industry (Group) Co. LTD, Zhengzhou, Henan 450042, China \\ ${ }^{3}$ School of Safety Engineering, North China Institute of Science and Technology, Beijing 101601, China \\ Correspondence should be addressed to Zhiheng Cheng; an958158@163.com and Liang Chen; 171753953@qq.com
}

Received 25 February 2021; Accepted 30 September 2021; Published 29 October 2021

Academic Editor: Jin Jiang

Copyright (C) $2021 \mathrm{Pu} \mathrm{Li} \mathrm{et} \mathrm{al.} \mathrm{This} \mathrm{is} \mathrm{an} \mathrm{open} \mathrm{access} \mathrm{article} \mathrm{distributed} \mathrm{under} \mathrm{the} \mathrm{Creative} \mathrm{Commons} \mathrm{Attribution} \mathrm{License,} \mathrm{which}$ permits unrestricted use, distribution, and reproduction in any medium, provided the original work is properly cited.

\begin{abstract}
The sealing depth of a gas-drainage borehole is critically important as it directly affects the efficiency of the whole drainage system. In order to determine the shortest reasonable sealing depth, in this paper, a theoretical drainage model using different sealing depths was proposed. Based on theoretical analysis presented, two parts of the fractures system surrounding the drainage borehole were proposed, i.e. the fractures induced by roadway excavation and the fractures induced by borehole drilling. A series of geological in-situ tests and simulations research were conducted to determine the stress and fracture distributions in the surrounding rock of the borehole. The depths of crushing zones, plastic zones and stress concentration zones were determined as $5 \mathrm{~m}, 2 \mathrm{~m}$ and $12 \mathrm{~m}$, respectively. Meanwhile, stress simulation shows that the depth of the stress concentration zone was $12 \mathrm{~m}$ from the roadway wall and the stress peak was located at the depth of $8 \mathrm{~m}$, which can be verified by the results of drilling penetration velocity analysis. To determine the optimum sealing depth, gas drainage holes with different sealing depths were drilled in the field. The field results revealed that the crushing zones were the main area for air leakage, and the stress concentration induced by roadway excavation assisted in the reduction of air leakage. Therefore, the optimized sealing depth should both cover the plastic zone and the stress concentration zone. The research achievements can provide a quantitative method for the determination of optimum sealing depth in cross-measure drainage boreholes.
\end{abstract}

\section{Introduction}

Coal mines in China have experienced the most serious coal and gas burst disasters in the world $[1,2]$. With the increasing depth of mining, stress in strata and gas pressure in coal seams increases while the permeability of coal seams decreases, which makes coal and gas burst disaster more serious [3-6]. It has been proved that releasing the gas energy by CBM drainage is one of the most effective ways to eliminate this disaster [7-11]. Meanwhile, coal-bed methane $(\mathrm{CBM})$ is a kind of clean energy (the heat of pure gas is more than $33 \mathrm{MJ} / \mathrm{m}^{3}$ ). Also, there are more than $36.81 \times 10^{12} \mathrm{~m}^{3}$ of gas in coal seams up to the depth of $2000 \mathrm{~m}$, which equals to $520 \times 10^{9}$ tons of standard coal by combustion heat $[4,12-14]$. Furthermore, the greenhouse effect of methane is 25 times stronger than that of $\mathrm{CO}_{2}$, which can cause severe damage to the ozone layer $[15,16]$. Therefore, extraction of CBM will not only be helpful to control the coal mine gasinduced disasters and to utilize this great source of clean energy but also to protect our environment [17-20].

The quantity of CBM drainage in China was 17 billion $\mathrm{m}^{3}$ in 2014, including 13.3 billion $\mathrm{m}^{3}$ extracted from underground, and this figure is increasing over time [21, 22]. CBM drainage in coal mines refers to a system which consists of boreholes pipes and pumps to extract the gas out from the coal seams, where the sealing of boreholes plays a critical important role to ensure its efficiency $[23,24]$. The air leakage during drainage occurs when the integrity of the borehole is poor, i.e. air flows into the borehole through excavation-induced fractures $[20,25,26]$. Nearly two-third of mines undertaking gas drainage in China use a short sealing length, and most of them use different standards of 
sealing depth, depending on their own experience [13, 27] or empirical formula calculation. Because of improper sealing techniques, the concentration of CBM drainage in $65 \%$ of actual working faces is less than $30 \%[22,28,29]$; there are many factors that affect the sealing effect, such as sealing material which cannot lead to larger deformation under certain stress level, sealer which resist the unbalanced force inside and outside the borehole and sealing depth which can resist the negative pressure of gas drainage and leave fewer blank bands.

Scholars have carried out lots of research to enhance the sealing quality of borehole, and some methods were proposed to determine the sealing depth via in-situ tests $[19,30-34]$. [20] analyzed the borehole drainage process by a compositional (CBM and air) model, and suggested that the air flow into the borehole through the excavationinduced fractures, which is the main cause for the air leakage of the borehole $[19,20,35]$. Suggested that the reasonable sealing depth should exceed the stress relief zone, which is the main area for the roadway excavationinduced fractures [36]. calculated the stress and physical state of the surrounding rock by FLAC ${ }^{3 \mathrm{D}}$ simulation and proposed that the sealing depth for the borehole should be beyond the stress concentration zone as there are some macro-fractures in this area [37]. suggested that rock with low permeability and high stress can prevent the air flowing into the borehole. He concluded that the sealing depth equals or exceed the depth of the maximum drilling sludge volume, due to the drilling sludge volume increase with the stress and permeability increase of the rock. In summary, the shortest reasonable sealing depth is closely related to the fracture and 'stress distribution in the surrounding rock. This is vital to take those factors into consideration to find out more precious sealing depth. Besides, due to the geological complexity of different mining areas. It is clear that conclusions were applicable in specific coal mines, although most of them are different but good drainage results were achieved. Meanwhile, none of them did any research based on different sealing depths.

In the present study, an analytical model was to the sealing qualities with different sealing depths was proposed. Then, a numerical simulation was carried out to study the stress and deformation distribution characters and a new method was proposed to determine the sealing depth based on the rate of penetration of the drilling rig and in-situ crack zone test by ultrasonic detection. Furthermore, this method was tested through gas drainage experiment with different sealing depths.

\section{Analysis of the Air Leakage with Different Sealing Depths}

As shown in Figure 1, after being excavated, the surrounding rock of the roadway can be divided into 3 zones, the crushing zone, the plastic zone and the elastic zone, in succession [17]. The strength of the crushing zone is smaller as there are lots of cracks and fractures in it [38], which leads to soaring permeability in this area [15]. Moreover, the stress in crushing zone is much smaller $s$ due to its low strength. As a result, the overburden of the upper layer strata shifts into the plastic zone, which leads to high stress concentration in this area. There exist some macro-fractures in the plastic zone as the stress exceeds its strength. Therefore, the permeability is higher than it is in the original stress zone [22]. Meanwhile, the permeability decreases due to the closure of cleats and the shrinkage of porous structure under high effective stress in the rock mass. And the permeability of porous rock can be calculated as equation (1) [7].

$$
k=k_{0} e^{-\mu\left(\sigma-\sigma_{0}\right)},
$$

where $\sigma_{0}$ is initial effective stress, $\sigma$ is effective stress, $-\mu$ is stress constant, $k_{0}$ is initial permeability of fractured rock mass, $k$ is the permeability of rock mass under stress.

Likewise, there also exist similar stress and permeability distribution characters in the surrounding rock of the borehole, therefore the air can also get into the borehole through these fractures. Furthermore, the leakage of air from the roadway flowing into the borehole is inevitable during the drainage process. However, as the sealing part is to prevent the air leakage from the roadway wall to the borehole, the air leakage volume can be reduced by improving the sealing depth.

According to Darcy's fluid law, the flow volume through the porous medium can be calculated as equation (2).

$$
Q=k \frac{\Delta p A}{\mu l},
$$

where $Q$ is the gas flow volume per unit time, $k$ is the permeability constant, $\Delta p$ is the gas pressure drop, $\mathrm{A}$ is the cross section area of the seepage zone, $\mu$ is the dynamic viscosity of the gas flow, $l$ is the seepage path length. Therefore, the air leakage volume with different sealing depths, as shown in Figure 1, can be calculated as equations (3) $-(5)$.

(1) The sealing depth equals the crushing zone (stress relief zone), i.e., $l=l_{0}$

$$
Q_{1}=k_{1} \frac{\Delta p A_{1}}{\mu l_{0}} .
$$

(2) The sealing depth equals the plastic zone, i.e., $l_{1}=l_{0}+\Delta l_{1}$

$$
Q_{2}=k_{2} \frac{\Delta p A_{2}}{\mu\left(l_{0}+\Delta l_{1}\right)} .
$$

(3) The sealing depth equals the stress concentration zone, i.e., $l_{2}=l_{0}+\Delta l_{1}+\Delta l_{2}$

$$
Q_{3}=k_{3} \frac{\Delta p A_{3}}{\mu\left(l_{0}+\Delta l_{1}+\Delta l_{2}\right)} .
$$

According to the analysis above, it is clear that $A_{1} / A_{2}>1$, and $l_{0}+\Delta l_{1} / l_{0}>1$, and $k_{1} / k_{2}>1$ combining equations (3) and (4), we obtain: 


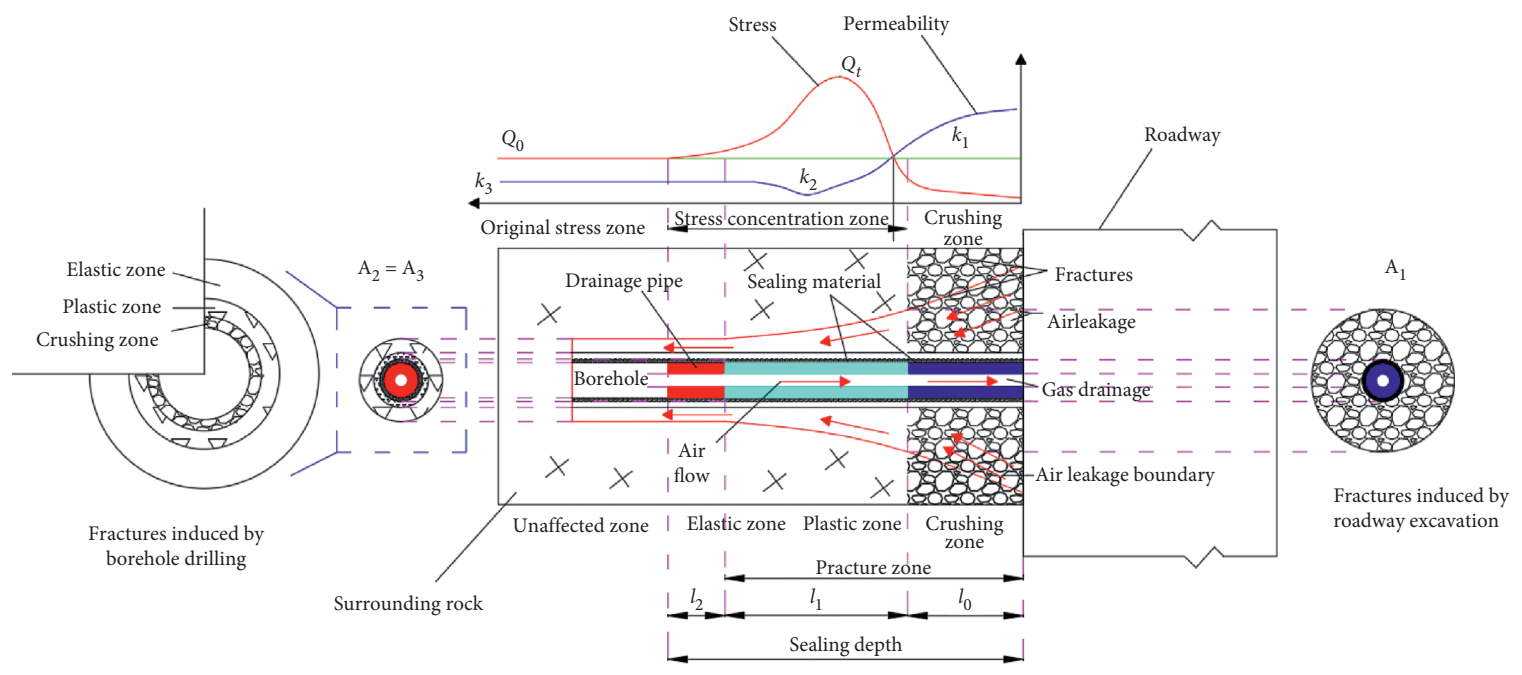

FIGURE 1: Distributions of stress and permeability in the surrounding rock of borehole.

$$
\frac{Q_{1}}{Q_{2}}=\frac{k_{1}}{k_{2}} \times \frac{A_{1}}{A_{2}} \times \frac{l_{0}+\Delta l_{1}}{l_{0}}>1 .
$$

Therefore, the air leakage volume can be dramatically reduced if the sealing depth is improved from $l_{0}$ to $l_{1}$.

Similarly, it is clear that $A_{2} / A_{3}=1, l_{1}+\Delta l_{2}+\Delta l_{3} / l_{0}+$ $\Delta l_{1}>1$ and $k_{2} / k_{3}=e^{\left(-\mu\left(\sigma-\sigma_{0}\right)\right)}$, combining equations (4) and (5), we obtain:

$$
\frac{Q_{2}}{Q_{3}}=\frac{k_{2}}{k_{3}} \times \frac{A_{2}}{A_{3}} \times \frac{l_{1}+\Delta l_{2}+\Delta l_{3}}{l_{0}+\Delta l_{1}}=n e^{-\mu\left(\sigma-\sigma_{0}\right)},
$$

where $n=A_{2} / A_{3} \times l_{1}+\Delta l_{2}+\Delta l_{3} / l_{0}+\Delta l_{1}>1$, however, $e^{-\mu\left(\sigma-\sigma_{0}\right)} \in[0,1]$, therefore it is unknown based on the equations if the sealing depth is improved from $l_{1}$ to $l_{2}$. Therefore, further research is needed to find out the shortest reasonable sealing depth.

\section{Optimization of the Sealing Depth}

3.1. Test Site. ShaQu coal mine is located in the Liliu mining area in the central section of Hedong Coalfield in the western of Shanxi province, China. The coal mine is characterized by extremely close distances between coal seams, and with high gas content and gas burst proneness. The coal series strata in the coalfield are composed of the Taiyuan formation in the Upper Carboniferous system and the Shanxi Formation in the Lower Permian system. In total there are 3 production coal seams with an average gas content of $10.34 \mathrm{~m}^{3} / t$, as shown in Table 1 . In order to eliminate the risk of gas burst disaster, the gas drainage roadway was excavated for gas drainage before the upper coal seam was mined, shown in Figure 2. The in-situ test research was held at the \#97 gas drainage drilling field of No.1 bed plate gas drainage roadway. The overburden depth is approximately $645 \mathrm{~m}$ and the main floor is sandstone. The cross-measure drainage boreholes were drilled in the drilling fields which were located along both sides of the roadway. The distribution of the drilling field and size of the road way are shown in Figure 3.
From the analysis in last section, there are two parts of fracture zones in the fracture system of surrounding rock. The first part is the fractures induced by the borehole drilling and the second part is the fractures induced by the roadway excavation, shown in Figure 1. Meanwhile, both the crushing zone and plastic zone in each part can lead to air leakage during the drainage process due to the fractures and cracks surrounding the borehole. However, the scale and magnitude of the fracture system induced by the roadway excavation is much larger than that of the borehole. Therefore, the main purpose of sealing part is to control the air leakage through the fractures induced by the roadway excavation. In this paper, we mainly focus on the fracture and stress distributions in the surrounding rock of the drilling field, which is part of the roadway and the place where the boreholes are set.

3.2. Analysis of Fracture Zone. Both the plastic zone and the crushing zone exists fractures, which is the path for air leakage in the drainage process. Therefore, these two parts are important to the determination of sealing depth. In this part, the plastic zone was calculated by FLAC $^{3 \mathrm{D}}$ simulation and the crushing zone was in-situ tested by ultrasonic detection.

3.2.1. Simulation Analysis of Plastic Zone. In order to replicate the same geological setting in Table 1 and Figure 3, a $3 \mathrm{D}$ model, where the size of the excavated roadway is $4 \mathrm{~m}$ (width) $\times 3 \mathrm{~m}$ (height) and the drilling field is $5 \mathrm{~m}$ (length) $\times$ $3 \mathrm{~m}$ (width) $\times 3 \mathrm{~m}$ (height), is created (shown in Figure 4). Mohr-Coulomb failure criterion was applied to represent plastic behavior of rock mass. The size of model is $30 \mathrm{~m}$ (width) $\times 30 \mathrm{~m}$ (length) $\times 20 \mathrm{~m}$ (height) which includes 165670 elements and 13468 nodes. The vertical stress applied for each element is $16 \mathrm{MPa}$ due to simulate the weight coming from the overburden strata of $640 \mathrm{~m}$ in depth and horizontal stress of $20 \mathrm{MPa}$ is also applied on the model based on the data of in-situ stress provided by Shaqu coal 
TABLE 1: Basic parameters of the coal seams.

\begin{tabular}{|c|c|c|c|c|}
\hline No. & Maximum original gas pressure (MPa) & Original gas content $\left(\mathrm{m}^{3} / t\right)$ & Permeability $\left(\mathrm{m}^{2} / \mathrm{MPa}^{2} \bullet \mathrm{d}\right)$ & Thickness $(\mathrm{m})$ \\
\hline$\# 3$ & 1.08 & $7-24.88$ & $1.78-1.89$ & 1.1 \\
\hline$\# 4$ & 1.30 & $7.3-17.82$ & $3.52-3.785$ & 2.2 \\
\hline$\# 5$ & 1.50 & $4.45-17.9$ & $1.99-.23$ & 3.77 \\
\hline
\end{tabular}

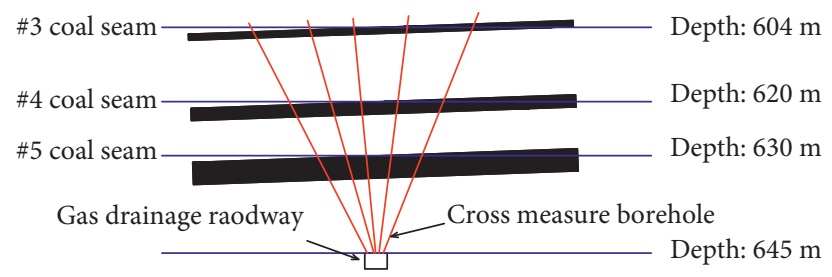

Figure 2: Illustration of the cross-measure boreholes in bed plate drainage roadway.
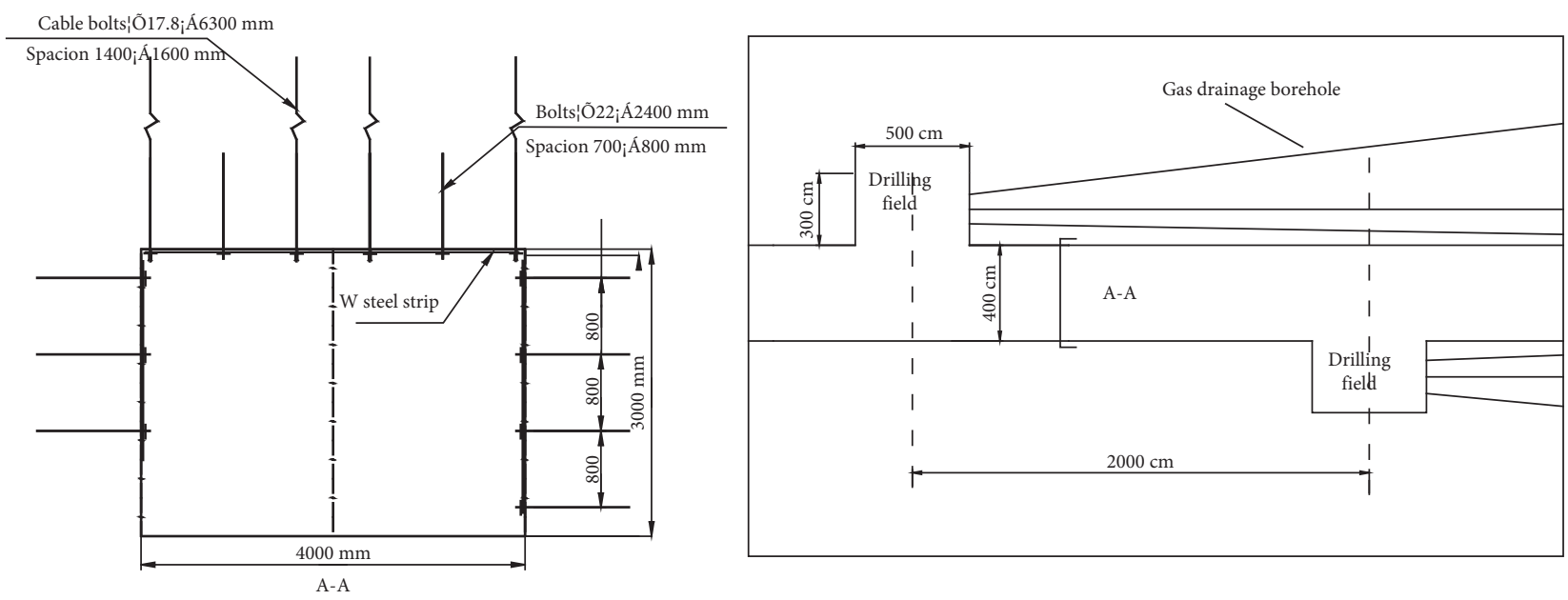

FIGURE 3: Distribution of drilling fields and drainage boreholes in the gas drainage roadway.

mine. The horizontal displacement of front, back, left, and right boundaries, as well as the vertical displacement of bottom are fixed. The mechanical parameters of the rock are shown in Table 2. Figure 4 shows the overburden strata and Figure 5 shows the mesh of the calculation model.

Figure 6 shows the distribution of plastic zone surround the drilling field and roadway. As the gas drainage boreholes mostly roll upward from the drilling field in $z$ direction, the plastic zone in this area puts more influence on the decision for the sealing depth. As shown in the results, the thickness of the plastic zone surrounding the drilling field reached $5 \mathrm{~m}$ in 2 direction and $2 \mathrm{~m}$ in 2 direction. While, it comes to $3.7 \mathrm{~m}$ in $x$ direction and also $5 \mathrm{~m}$ in $z$ direction for thickness of plastic zone in the surrounding rock of roadway.

3.2.2. In-Situ Crushing Zone Test by Ultrasonic Detection. Ultrasonic detection has been adopted for detecting the crushing zone in the surrounding rock by researchers $[11,18,22,38]$. The principles of the test are as follows: the velocity of the ultrasonic wave attenuates significantly due to the reflection and refraction effects between the interfaces among the discontinuous fractures in the crushing zone and the duration time in certain distance increases rapidly with the number of fractures mounts. While the velocity of the ultrasonic wave attenuates slightly when the number of cracks decreases and the reflection and refraction effects drops. In other words, there exists a positive relationship between the duration of time of ultrasonic wave and the degree of deformation in the surrounding rock. Therefore, the distribution characters of the crack zone can be found by recording the duration time of the ultrasonic wave.

In this paper, the ultrasonic detection analyzer (BA-II, CCRI Co, Ltd) was adopted to test the duration time of ultrasonic wave in the rock of the drilling field. This analyzer consists of 3 parts which are the probe the host computer and the connecting wires as is shown in Figure 7 . The transmitter and receiver are set in the probe with the length of $1 \mathrm{~m}$. Therefore, the host computer will record the duration time and calculate the velocity of the ultrasonic wave based on the signals between the transmitter and receiver, shown in equation (8). The boreholes were tested $0.1 \mathrm{~m}$ by each step in depth. The arrangement of the two test boreholes are shown in Figure 8. Figure 9 shows the test results. 


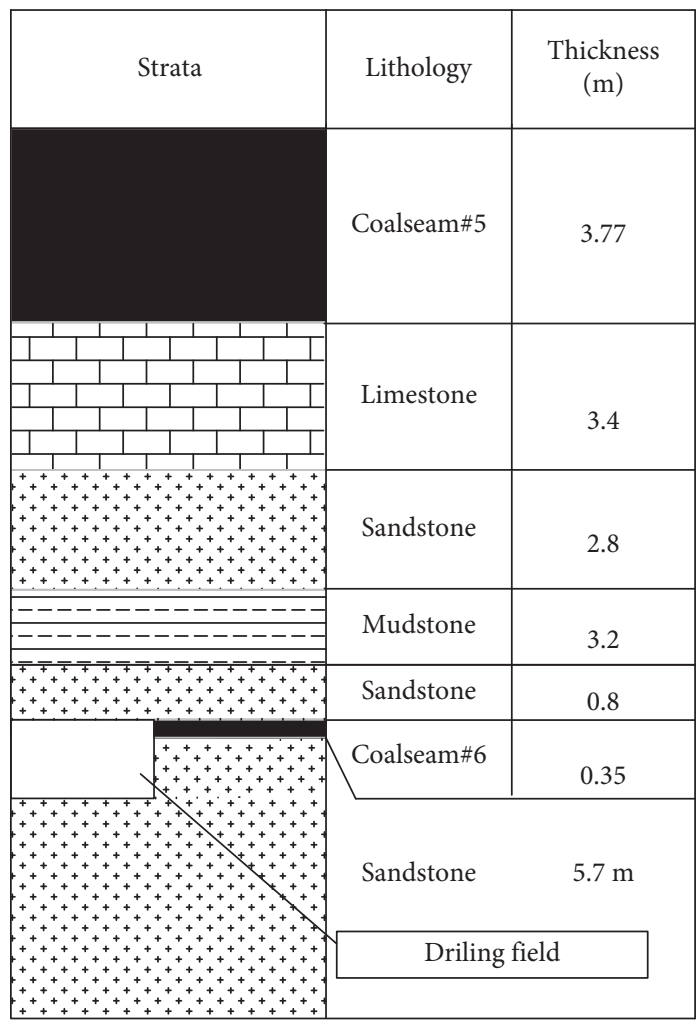

FIgURE 4: Stratigraphic column and position of the bed floor tunnel.

TABLE 2: Mechanical parameters of the surrounding rock of the drilling field.

\begin{tabular}{lcccccc}
\hline No & Lithology & Elastic modulus $(\mathrm{MPa})$ & Compression strength $(\mathrm{MPa})$ & Density $\left(10^{-5} \mathrm{~N} \cdot \mathrm{mm}^{-3}\right)$ & Friction angle $\left(^{\circ}\right)$ & Cohesion $(\mathrm{MPa})$ \\
\hline 1 & Mudstone & 20 & 25 & 2.4 & 25 & 10 \\
2 & Coal seam \#5 & 10 & 15 & 1.4 & 20 & 1.8 \\
3 & Sandstone & 64 & 76 & 2.6 & 27 & 20 \\
4 & Limestone & 18 & 20 & 2.2 & 1.4 & 24 \\
5 & Coal seam \#6 & 10 & 15 & 15 & 1.5 \\
\hline
\end{tabular}

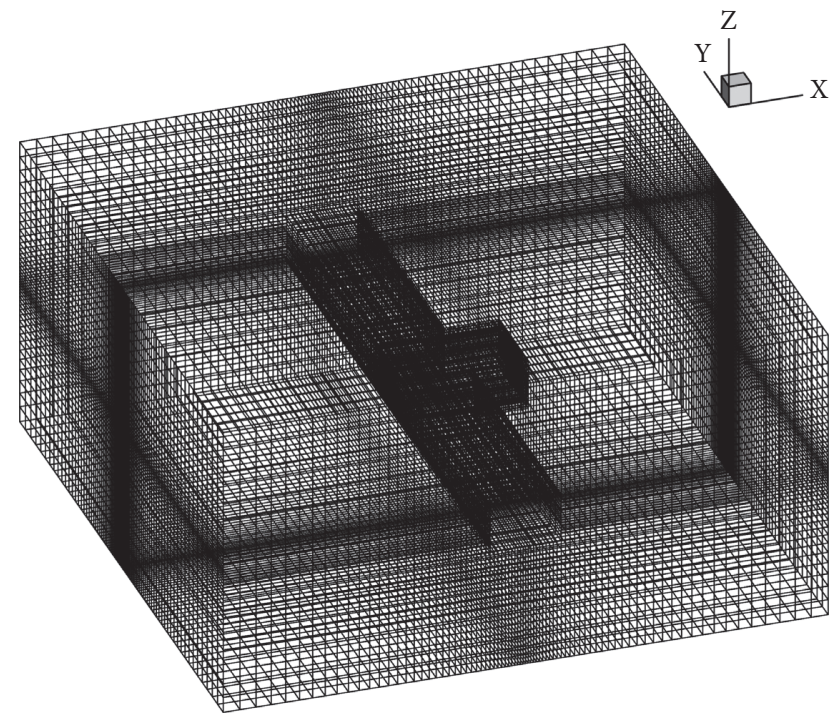

FIgURE 5: 3D mesh of the numerical model.

$$
V=\frac{L}{t}
$$

where $L$ is the distance of the transmitter and receiver and $L=1 \mathrm{~m}, t$ is the duration time the ultrasonic wave reaches the receiver coming from the transmitter, $\mathrm{V}$ is the velocity of the ultrasonic wave.

As the curves show in Figure 9, the duration time of the ultrasonic wave drops significantly at the depth of $0-2.0 \mathrm{~m}$ and it fluctuated at $45 \mathrm{~ms} / \mathrm{m}$ slightly afterwards, which infers that the velocity increases in this area and the number of fractures and cracks induced by the excavation has decreased in this area. Therefore, the boundary of the crushing zone locates at the depth of $2.0 \mathrm{~m}$.

3.3. Stress State of the Drilling Field. From the analysis above, the redistributed stress can significantly change the permeability of the rock mass. The permeability in the stress concentration zone decreases due to cleats closure and macro-pores shrinkage. While the permeability in the stress 


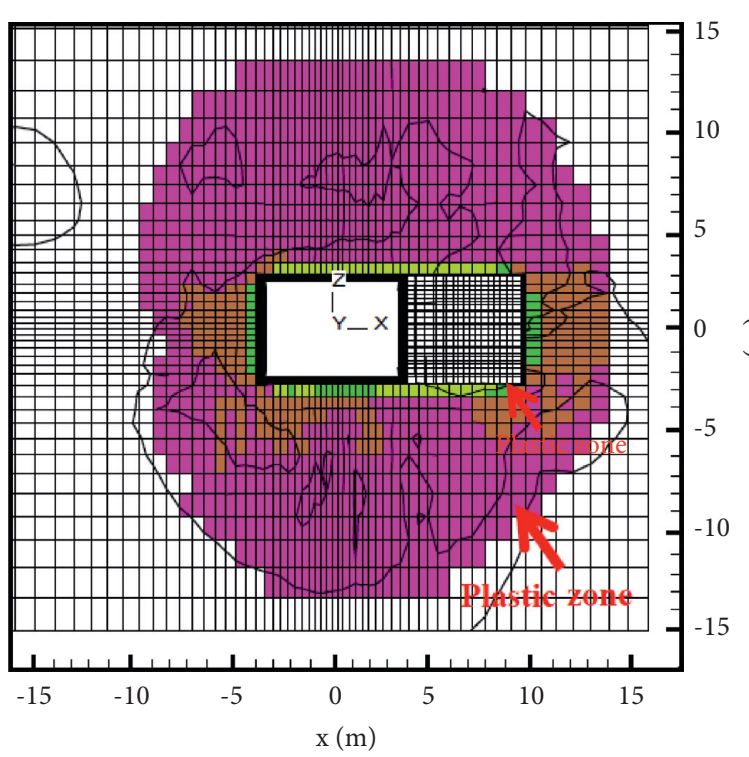

(a)

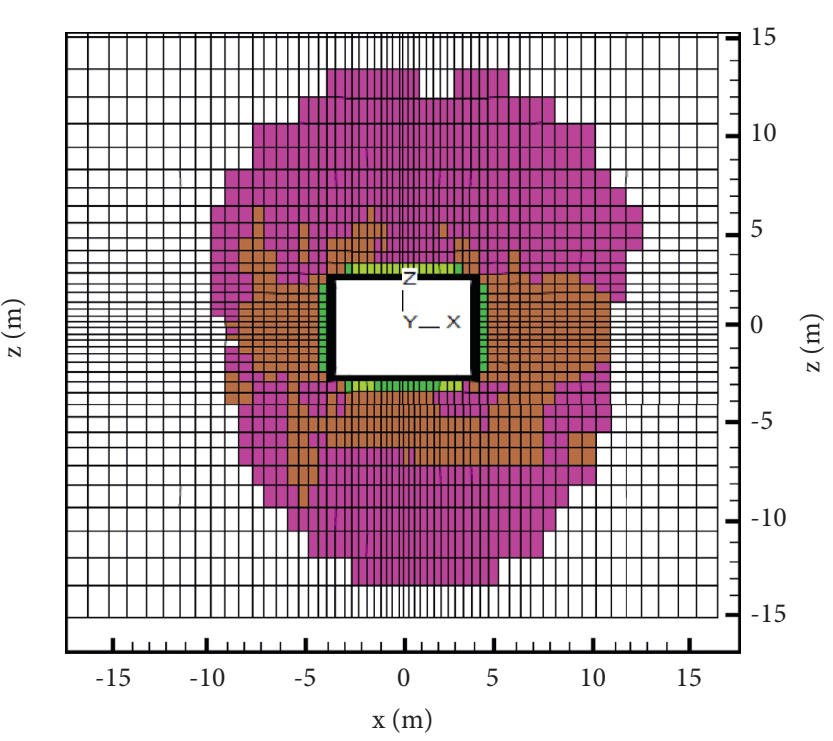

(b)

Figure 6: Vertical cross section distribution of the plastic zone in surrounding rock. (a) Drilling field. (b) Roadway.

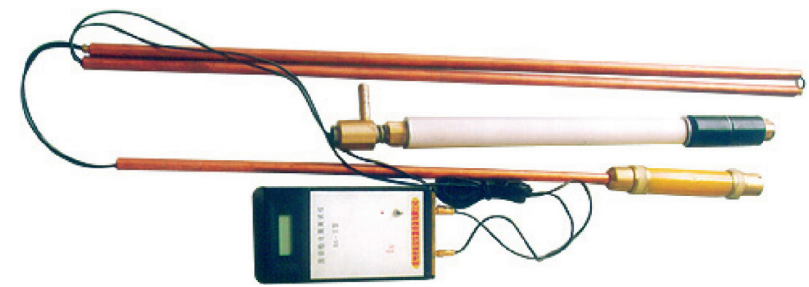

Figure 7: The ultrasonic detection analyzer unit.

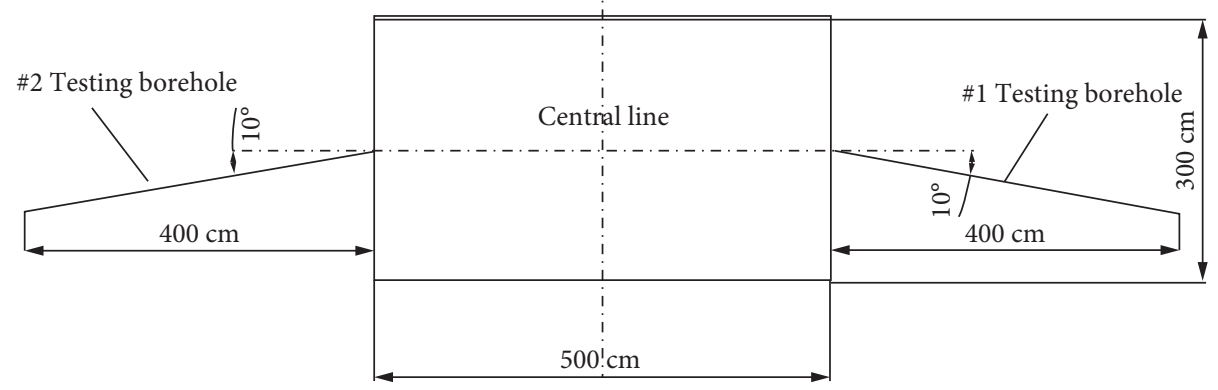

Figure 8: Arrangement of the boreholes for ultrasonic detection.

increases due to the swell of rock mass and cleats open. Therefore, the stress distribution is an important factor for the determination of sealing depth except for the fracture zone. In this paper, the stress distribution was calculated by FLAC $^{3 \mathrm{D}}$ simulation and in-situ analyzed by the results of penetration velocity of drilling rod in the surrounding rock during the borehole drilling process.

3.3.1. FLAC ${ }^{3 D}$ Simulation. Based on the calculation model above, the vertical stress cloud contour on the horizontal cross section of the drilling field can be achieved, shown in
Figure 10. Two main characters can be drawn from this result: firstly, the vertical stress in the $y$ direction of the surrounding rock shows high concentration. Secondly, the vertical stress decreases as the distance from the drilling field increases until it falls to the virgin field stress of $16 \mathrm{MPa}$ at the distance around $12 \mathrm{~m}$ and the high vertical stress area (20-22 MPa) locates at the depth of 7-8 m. Taking the contour of $16 \mathrm{MPa}$ as the boundary of the stress concentration zone, it is clear that the excavation-induced stress concentration zone reaches as far as $12 \mathrm{~m}$. While, the vertical stress reaches its top $(22 \mathrm{MPa})$ around the depth of 7-8 m. 


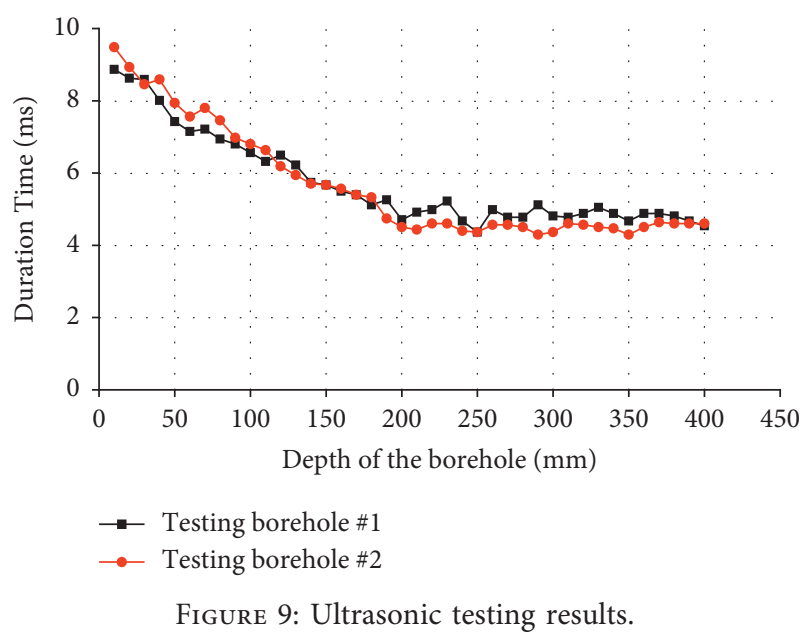

3.3.2. Stress Concentration Zone Analysis through Drilling Response. Drilling torque is the stress that the bit imposes on the rock during the drilling process. The value of the drilling torque depends on the size of the borehole, rate of penetration and drilling power, shown in equation (9) [24]. During the drilling process, the drilling torque may get unstable mainly caused by the change of the physical characters of the surrounding rock, such as the strength or the stress concentration characters. Given that the drilling constant and the drilling power $\mathrm{W}$ are fixed, the drilling torque $T$ decreases as the surrounding rock gets less stress concentration or strength, the rate of penetration will increase. Likewise, when the drilling torque $T$ increases as the surrounding rock gets more stress concentration or strength, the rate of penetration will decrease [39]. The curve of the rate of penetration against the drilling torque is shown in Figure 11.

$$
T=c \frac{W}{v}
$$

where $c$ is a drilling constant which is determined by the diameter of the borehole and the rotational speed of the drilling pipe, $v$ is the rate of penetration and $\mathrm{W}$ is the drilling power.

The drilling duration time was recorded based on 4 testing boreholes. The basic parameters were shown in Figure 12 and Table 3. The in-situ drilling duration time and rate of penetration are tested $1 \mathrm{~m}$ by each step due to the length of the drill pipe is $1 \mathrm{~m}$. As is shown in Figure 13, the testing curves have shown similar trends with the drilling depth goes up. Meanwhile, the rate of penetration has seen significant drop while the duration time soared up during the depth of $0-8 \mathrm{~m}$. Moreover, the curves meet their turning point at the depth of 7-8 $\mathrm{m}$. However, the rate of penetration gradually bounced back and the duration time decreases sharply after the drilling depth exceeds $8 \mathrm{~m}$. The drop of the rate of penetration is mainly caused by the friction of drilling pipe due to the stress concentration in the surrounding rock. Therefore, it can be seen that the maximum stress concentration area locates at the depth of 7-8 $\mathrm{m}$ of the borehole, which verifies the simulation results.

\section{Gas Drainage Test via Cross- Measure Boreholes}

It can be concluded from Section 3 that the boundary of the crushing zone (B1), plastic zone (B2) and stress concentration zone (B3) is located at the depths of $2 \mathrm{~m}, 5 \mathrm{~m}$ and $12 \mathrm{~m}$ respectively. In order to determine the shortest sealing depth of the cross-measure gas drainage borehole, a contrast gas drainage experiment based on different sealing depths has been conducted. This experiment was to determine the relationship of the optimized sealing depth between the depths of B1, B2 and B3. Therefore, three contrasting experimental drainage groups were formed and each group has a unique sealing depth. The sealing depth for group 1 is $2 \mathrm{~m}$ which equals the depth of B1. The sealing depth for group 2 is $5 \mathrm{~m}$ which equals the depth of B2. And the sealing depth for group 3 is $12 \mathrm{~m}$ which equals the depth of B3. Table 4 shows the parameters of each borehole and Figure 14 shows the illustration for the sealing process. In order to minimize the influence from unstable drainage performance of single drainage borehole, each experiment group consists of 3 independent boreholes. Furthermore, the boreholes in each group are at interlaced arrangement to minimize the influence from the inhomogeneity of the coal-bed gas geology. Three monitoring lines group these boreholes to get the drainage performance data, shown in Figure 15.

The gas flow is the total mixed gas extracted out from the coal seam which consists of two parts, namely, the pure methane and air (other gas components). Therefore, the pure methane volume can be calculated by the product of methane concentration and gas flow volume. In this experiment, the monitoring was initiated immediately after the boreholes were sealed and connected to the drainage system. The gas concentration and the gas flow volume of each drainage borehole were monitored for every other day in the following 60 days during the drainage process. The drainage results of methane concentration of three monitoring lines were shown in Figure 16-18. Two main conclusions can be drawn from these curves. Firstly, the methane concentration in three monitoring lines stayed high in the early stage (day $0-10)$ of the drainage process. Then a negative exponential decline is observed due to the residual coal seam gas decreasing, which applies to all drainage boreholes. Secondly, the results of group $2(l=10 \mathrm{~m})$ and $3(l=15 \mathrm{~m})$ were comparable during the whole drainage process. While, the gas concentration of the group $1(l=5 \mathrm{~m})$ were significantly lower than that of group $2(l=5 \mathrm{~m})$ and group $3(l=15 \mathrm{~m})$.

Tables 5 and 6 show the drainage performance of each borehole and each group respectively. Based on the results shown in Table 6 , it is clear that the methane concentration of group $1(15.1 \%)$ is lower than half that of group $2(46.2 \%)$ and group $3(51.6 \%)$, while the gas flow volume $(18.9 \mathrm{~L} / \mathrm{min})$ is significantly higher than the rest two groups $(13.9 \mathrm{~L} / \mathrm{min}$ and $12.5 \mathrm{~L} / \mathrm{min}$, respectively). As a result, the pure gas volume of group $1(2.8 \mathrm{~L} / \mathrm{min})$ is $50 \%$ less than that of group $2(6.3 \mathrm{~L} / \mathrm{min})$ and group $3(6.5 \mathrm{~L} / \mathrm{min})$. The direct cause for the low drainage efficiency of group 1 is, because of insufficient sealing depth, the air in the roadway flow into the 


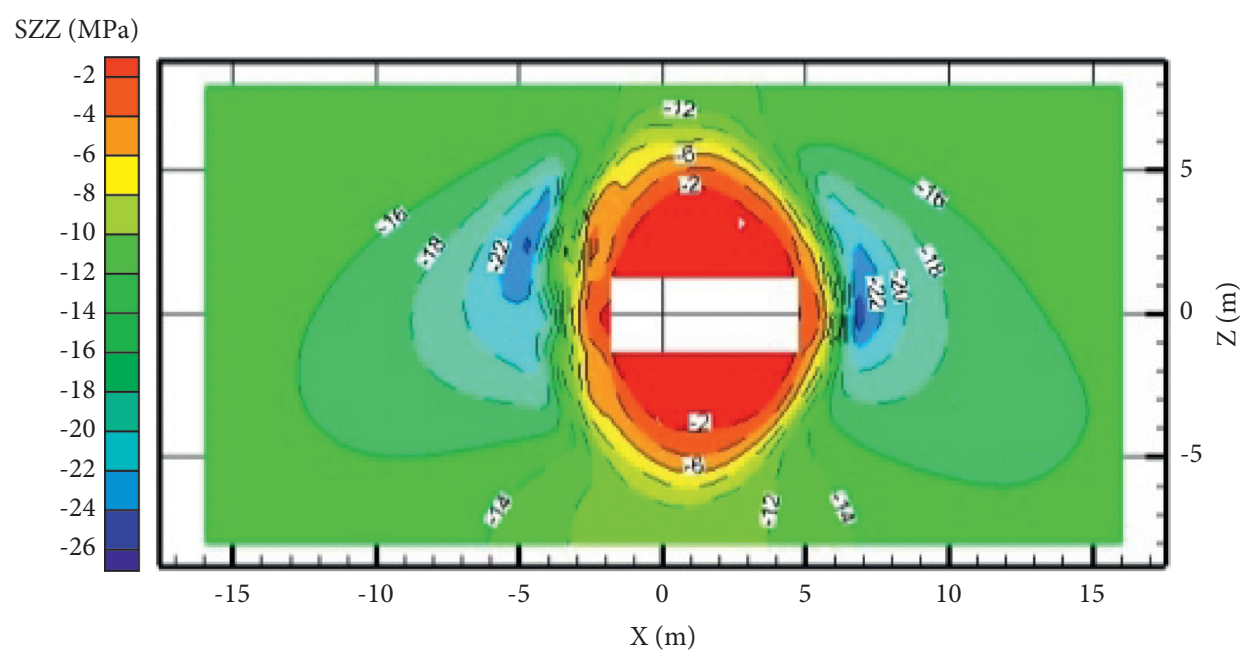

(a)

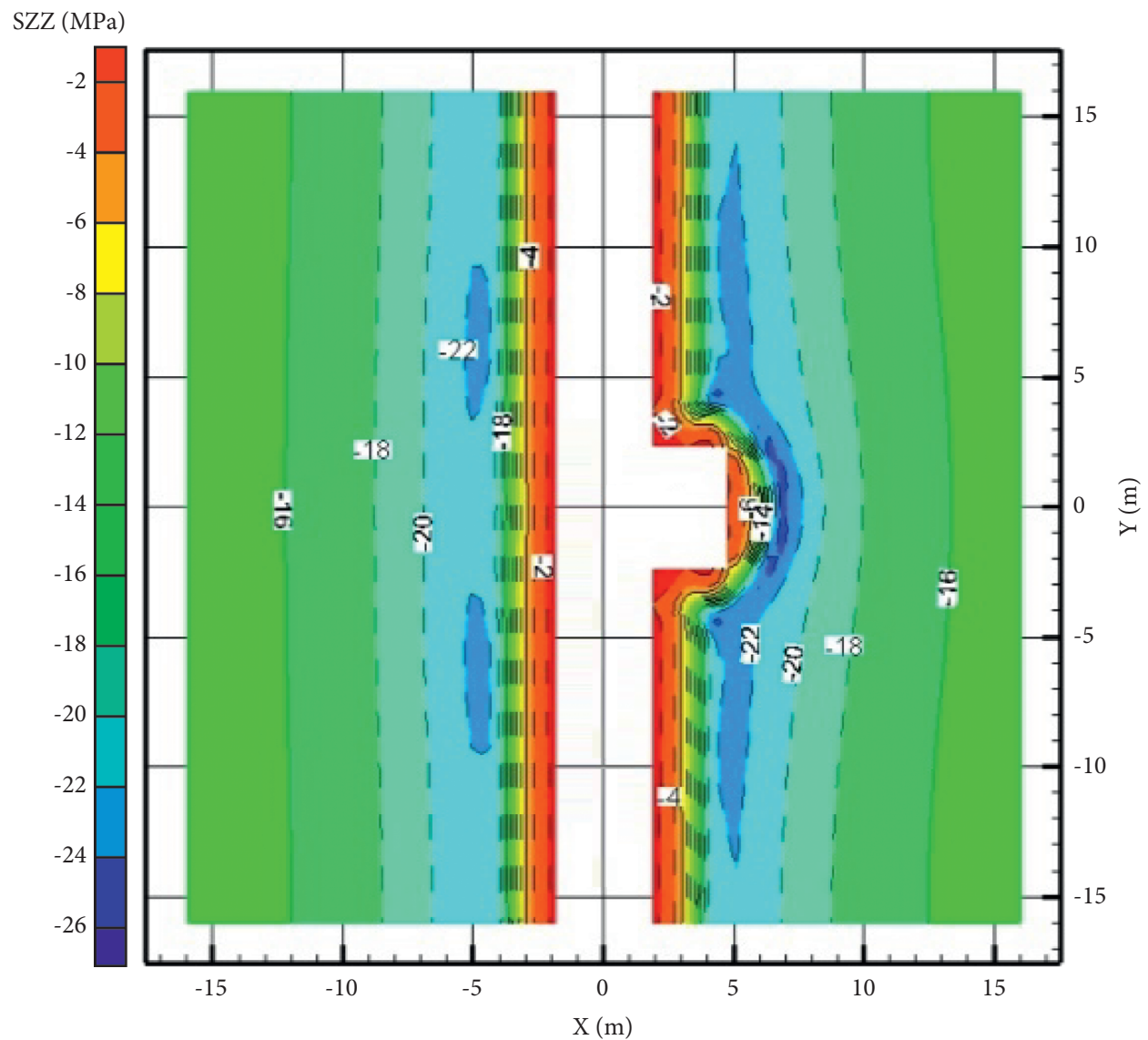

(b)

FIgURE 10: Vertical stress cloud contour in the surrounding rock. (a) Vertical cross section via the central of drilling field. (b) Horizontal cross section via the central of roadway.

borehole through the fracture system (both the fractures induced by the roadway excavation and borehole drilling) in the surrounding rock of the drilling field. Therefore, this result verifies that the air leakage volume can be dramatically reduced if the sealing depth is improved from the crushing zone (group 1) to the plastic zone (group 2), as shown in equation (6). Meanwhile, though both the sealing depths of group 2 and group 3 exceed the fracture zone induced by the roadway excavation, the methane concentration of group 2 (46.2\%) is still $10.4 \%$ less than that of group $3(51.6 \%)$, which indicates there still exist air leakage in group 2 . A reasonable explanation is that, though the air leakage of drainage borehole is unavoidable due to the fracture system induced by the borehole drilling, the leakage volume still can be 


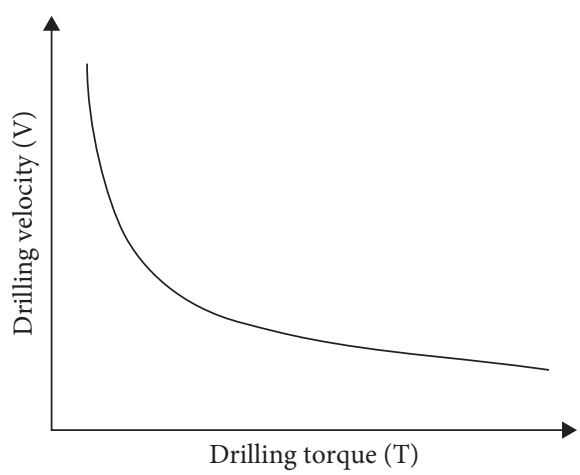

FIGURE 11: Curve of rate of penetration against drilling torque under fixed drilling power.

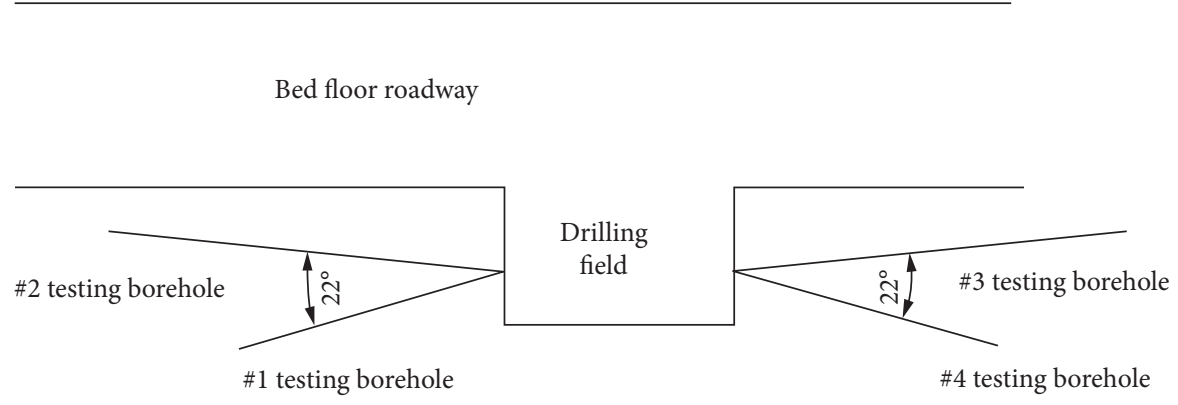

FIgURE 12: Arrangement of the testing boreholes.

TABle 3: Parameters of the testing boreholes.

\begin{tabular}{lcccccc}
\hline No. & Diameter $(\mathrm{mm})$ & Dip angle $\left(^{\circ}\right)$ & Length $(\mathrm{m})$ & Surrounding rock & Drilling power $(\mathrm{KW})$ & Drilling rig \\
\hline$\# 1$ & 94 & 15 & 12 & Sandstone & 45 & ZDY-4000L \\
$\# 2$ & 94 & 15 & 12 & Sandstone & 45 & ZDY-4000L \\
$\# 3$ & 94 & 15 & 12 & Sandstone & 45 & ZDY-4000L \\
$\# 4$ & 94 & 15 & 12 & Sandstone & 45 & ZDY-4000L \\
\hline
\end{tabular}

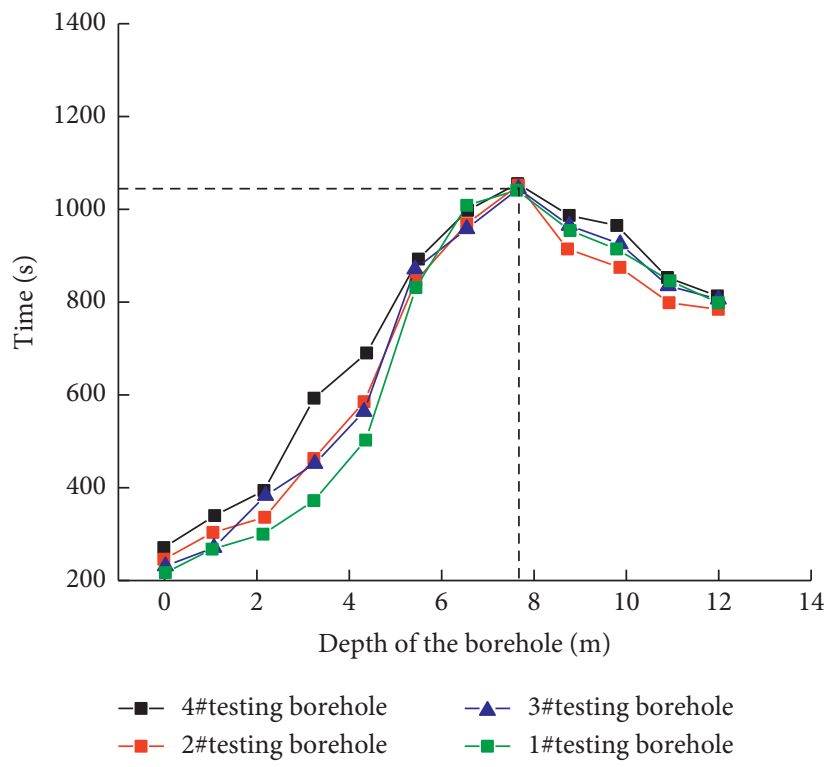

FIgURE 13: Curves of drilling time against rate of penetration. 
TABLE 4: Basic parameters of the experiment boreholes.

\begin{tabular}{lccccc}
\hline Borehole no. & Diameter $(\mathrm{mm})$ & Dip angle $\left(^{\circ}\right)$ & Length $(\mathrm{m})$ & Sealing depth $(\mathrm{m})$ & Group no. \\
\hline$\# 1-1$ & 94 & 5 & 142 & 5 & 5 \\
$\# 1-2$ & 94 & 9 & 80 & 5 & 1 \\
$\# 1-3$ & 94 & 13 & 56 & 10 & 1 \\
$\# 2-1$ & 94 & 5 & 142 & 10 & 2 \\
$\# 2-2$ & 94 & 9 & 54 & 10 & 2 \\
$\#-3$ & 94 & 13 & 140 & 15 & 3 \\
$\# 3-1$ & 94 & 5 & 82 & 56 & 3 \\
$\# 3-3$ & 94 & 9 & 56 & 15 & 3 \\
\hline
\end{tabular}

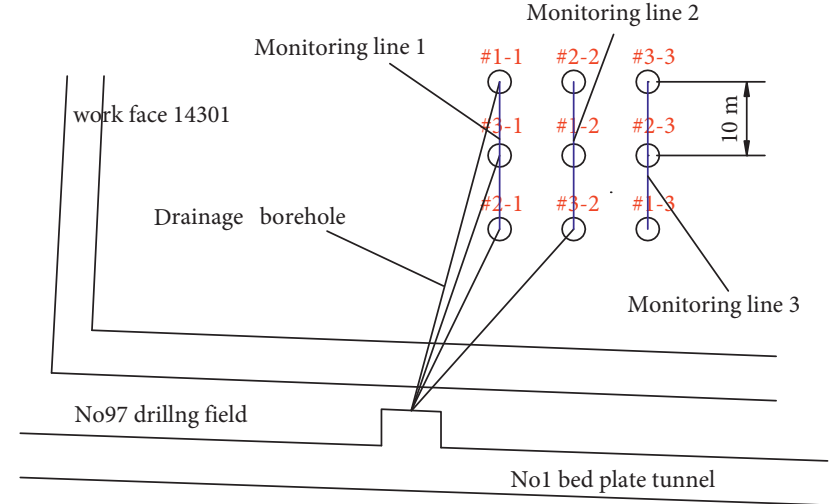

Figure 14: Simplified schematic of the borehole sealing in the drilling field.

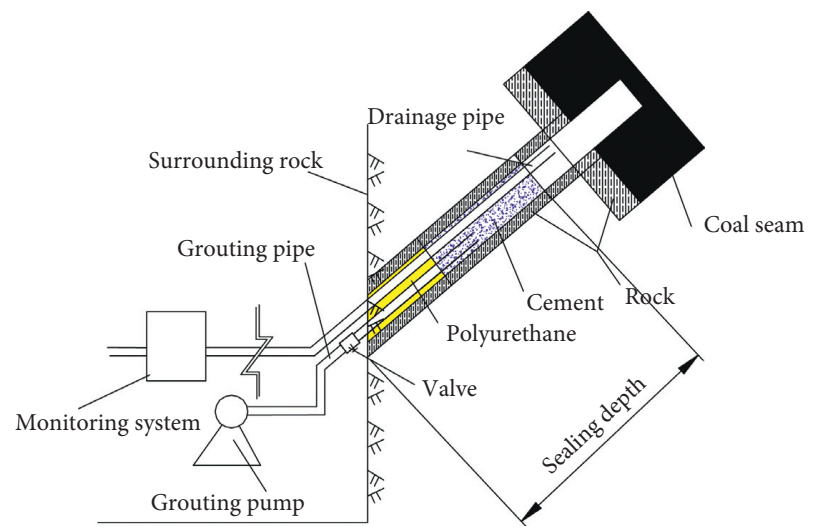

FIGURE 15: Arrangement of the experiment boreholes.

reduced by improving the sealing depth. Meanwhile, as shown in equation (7), it can be concluded $Q_{2} / Q_{3}=k_{2} / k_{3} \times$ $A_{2} / A_{3} \times l_{1}+\Delta l_{2}+\Delta l_{3} / l_{0}+\Delta l_{1}=n e^{-\mu\left(\sigma-\sigma_{0}\right)}>1$.

In summary, the drainage result has verified the theoretical analysis of air leakage volume using different sealing depth. Meanwhile, three conclusions can be drawn based on the analysis above, firstly, the air leakage decreases with the increase of sealing depth, especially when the sealing depth is less than the crushing zone. Secondly, the fractures induced by roadway excavation are the main path for air leakage of the borehole. Thirdly, the permeability decrease caused by stress concentration is helpful to prevent the air flowing into the borehole through the fractures. Moreover, based on the

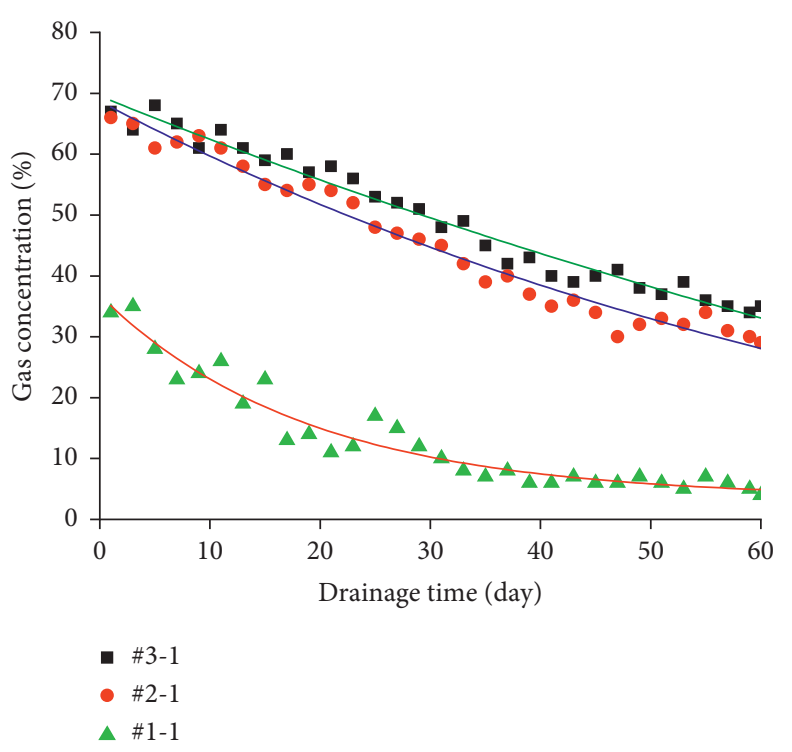

FIgURE 16: Curves of gas concentration in boreholes at monitor line 1 .

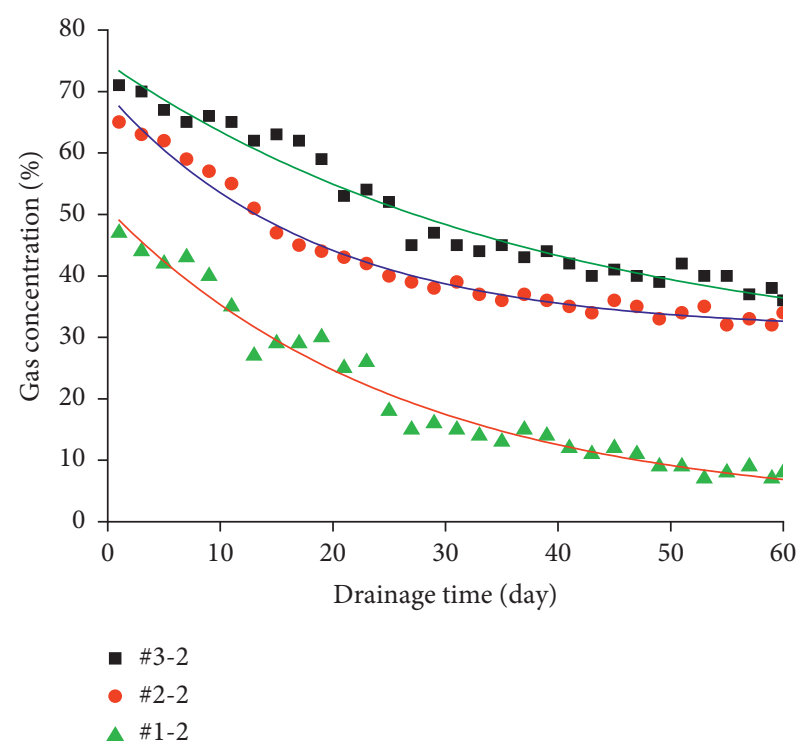

FIgURE 17: Curves of gas concentration in boreholes at monitor line 2. 


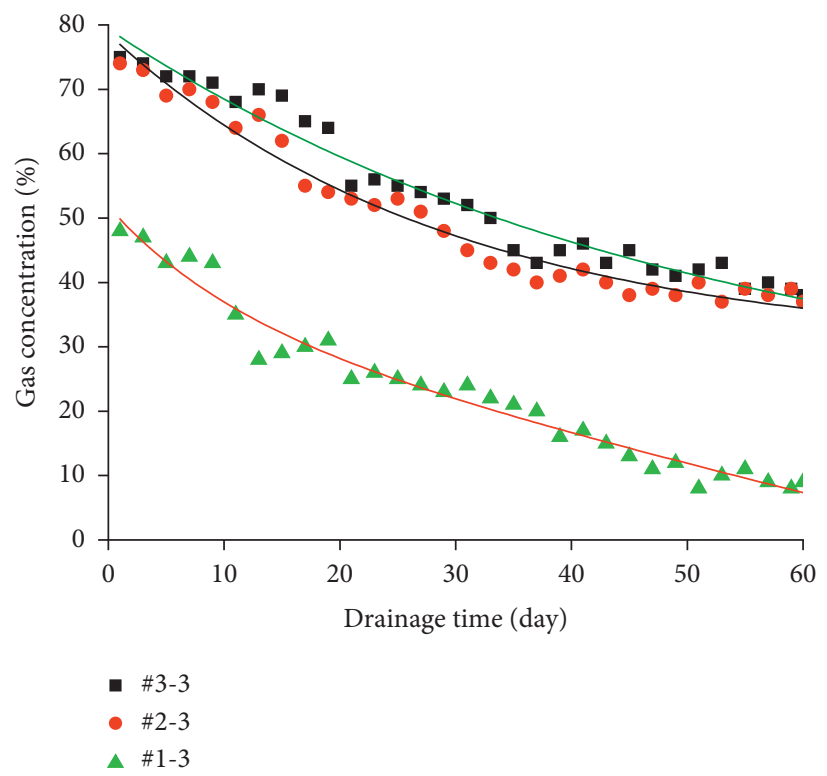

Figure 18: Curves of gas concentration in boreholes at monitor line 3.

TABLE 5: Drainage results of each test borehole.

\begin{tabular}{|c|c|c|c|c|c|c|}
\hline $\begin{array}{l}\text { Borehole } \\
\text { no. }\end{array}$ & $\begin{array}{c}\text { Methane concentration } \\
(\%)\end{array}$ & $\begin{array}{c}\text { Gas flow volume } \\
(\mathrm{L} / \mathrm{min})\end{array}$ & $\begin{array}{l}\text { Pure methane volume } \\
(\mathrm{L} / \mathrm{min})\end{array}$ & $\begin{array}{l}\text { Drainage pressure } \\
(\mathrm{kPa})\end{array}$ & $\begin{array}{l}\text { Sealing depth } \\
(\mathrm{m})\end{array}$ & $\begin{array}{c}\text { Group } \\
\text { no. }\end{array}$ \\
\hline$\# 1-1$ & 13.5 & 20.3 & 2.74 & -13 & 5 & 1 \\
\hline$\# 1-2$ & 15.1 & 18.8 & 2.83 & -13 & 5 & 1 \\
\hline$\# 1-3$ & 16.9 & 17.5 & 2.95 & -13 & 5 & 1 \\
\hline$\# 2-1$ & 46 & 13.8 & 6.34 & -13 & 10 & 2 \\
\hline$\# 2-2$ & 42.4 & 14.8 & 6.27 & -13 & 10 & 2 \\
\hline$\# 2-3$ & 50.3 & 13.0 & 6.43 & -13 & 10 & 2 \\
\hline$\# 3-1$ & 50.1 & 12.8 & 6.41 & -13 & 15 & 3 \\
\hline \#3-2 & 50.6 & 12.7 & 6.42 & -13 & 15 & 3 \\
\hline \#3-3 & 54.1 & 12.1 & 6.54 & -13 & 15 & 3 \\
\hline
\end{tabular}

TABle 6: Drainage results of each group.

\begin{tabular}{lcccc}
\hline Group no. & Methane concentration (\%) & Gas flow volume (L/min) & Pure methane volume (L/min) & Sealing depth (m) \\
\hline 1 & 15.1 & 18.9 & 2.8 & 5 \\
2 & 46.2 & 13.9 & 6.3 & 10 \\
3 & 51.6 & 12.5 & 6.5 & 15 \\
\hline
\end{tabular}

drainage performance of 3 groups, the optimized shortest sealing depth for the cross-measure borehole is $12 \mathrm{~m}$, which should cover both the plastic zone and stress concentration zone.

\section{Conclusions}

To optimize the sealing depth of the cross-measure drainage borehole, a theoretical model was proposed to analyze the air leakage volume using different sealing depths. A series of insitu tests were conducted for verification and further research. Based on the results of tests and analysis, the following conclusions can be drawn:

(1) Based on theoretical analysis presented, two parts of the fractures system surrounding the drainage borehole were proposed, i.e. the fractures induced by roadway excavation and the fractures induced by borehole drilling. Both parts can lead to air leakage of the drainage borehole. The first part consists of crushing zone and plastic zone. And the crushing zone is the main path for air leakage, which can be reduced by improving sealing depth. However, for the second part, the air leakage volume is affected by the stress concentration induced by roadway excavation.

(2) The stress and fracture distributions were analyzed by in-situ test and numerical simulation. The results show that the thickness of the plastic zone and the crushing zone was $5 \mathrm{~m}$ and $2 \mathrm{~m}$, respectively. Meanwhile, stress simulation shows that the depth of the stress concentration zone was $12 \mathrm{~m}$ from the roadway wall and the stress peak was located at the 
depth of $8 \mathrm{~m}$, which can be verified by the results of drilling penetration velocity analysis.

(3) The drainage contrast experiment revealed that, though the air leakage volume decreased with the increase of sealing depth. However, different sealing depth stages have their unique causes. In the first stage, when the sealing depth was improved from crushing zone to plastic zone, the air leakage volume decreased due to the sealing material preventing the air flowing into the borehole through the fractures in the crushing zone. While in the second stage, when the sealing depth was improved from the plastic zone to the stress concentration zone, the air leakage volume decreased due to the permeability decrease caused by high stress imposing on the fractures induced by borehole drilling. The study case shows that the shortest optimized sealing depth is $12 \mathrm{~m}$, which should both cover the plastic zone and the stress concentration zone [40].

\section{Data Availability}

The data used to support the findings of this study are currently under embargo while the research findings are commercialized. Requests for data, after publication of this article, will be considered by the corresponding authors.

\section{Conflicts of Interest}

The authors declare that they have no conflicts of interest.

\section{Acknowledgments}

This work is financially supported by National Natural Science Foundation of China (51774110), Program for Science and Technology Innovation Talents in Universities of Henan Province (19HASTIT047) and Science and Technology Project of Henan Province (182102310012), which are gratefully acknowledged.

\section{References}

[1] P. Wei, X. Li, S. Peng, and C. Huang, "Numerical simulation of boreholes for gas extraction and effective range of gas extraction in soft coal seams," Energy Science \& Engineering, vol. 7, no. 5, pp. 1632-1648, 2019.

[2] Q. X. Yu and Y. P. Cheng, "Mine gas prevention and control," China University of Mining and Technology Press, vol. 12, no. 3, pp. 51-59, 2012.

[3] D. J. Black, "Review of coal and gas outburst in Australian underground coal mines," International Journal of Mining Science and Technology, vol. 29, no. 6, pp. 815-824, 2019.

[4] M. Cai, H. Peng, and H. Ji, "New development of hydraulic fracturing technique for in-situ stress measurement at great depth of mines," Journal of University of Science and Technology Beijing, vol. 15, no. 6, pp. 665-670, 2008.

[5] Q. Hu and X. Zhao, "Suggestions and countermeasures on the current situation of coal and gas outburst in China," Ming safety \& environmental protection, vol. 39, no. 5, pp. 1-5, 2012.

[6] T. Liu, B. Lin, and X. Fu, "Mechanical criterion for coal and gas outburst: a perspective from multiphysics coupling,"
International Journal of Coal Science \& Technology (prepublish), 2021.

[7] D. Chen, P. Zhejun, Y. Zhihui, H. Bing, W. Di, and Y. Liang, "A unified permeability and effective stress relationship for porous and fractured reservoir rocks," Journal of Natural Gas Science and Engineering, vol. 29, pp. 401-412, 2016.

[8] Y. Cheng, J. Fu, and Q. Yu, "Development of gas extraction technology in coal mines of China," Journal of Mining\& Safety Engineering, vol. 26, no. 2, pp. 127-139, 2009.

[9] H. Gao, Q. Wang, J. Bei, and P. Zhang, "Relationship between rock uniaxial compressive strength and digital core drilling parameters and its forecast method," International Journal of Coal Science \& Technology (prepublish) Technology, vol. 8, no. 3, 2021.

[10] D. Rudakov and V. Sobolev, "A mathematical model of gas flow during coal outburst initiation," International Journal of Mining Science and Technology, vol. 29, no. 5, pp. 791-796, 2019.

[11] X. Wu, Y. Peng, J. Xu, Q. Yan, W. Nie, and T. Zhang, "Experimental study on evolution law for particle breakage during coal and gas outburst," International Journal of Coal Science \& Technology, vol. 7, no. 1, pp. 97-106, 2020.

[12] P. F. Cui, Y. Banghua, L. Yong, W. Jianping, W. Zhihui, and L. Hui, "A new width measurement method of the stress relief zone on roadway surrounding rocks," Geofluids, vol. 2019, pp. 331-322, Article ID 9519353, 2019.

[13] C. Peng, "Present situation and problems of gas drainage and utilization in coal mines in China," Safety In Coal Mines, vol. 33, no. 2, pp. 62-65, 2007.

[14] Q. Zou, H. Liu, Z. Cheng, and T. Zhang, "Effect of slot inclination angle and borehole-slot ratio on mechanical property of pre-cracked coal: implications for ecbm recovery using hydraulic slotting," Natural Resources Research, vol. 29, pp. 1705-1729, 2019.

[15] S. Hu, Y. Liu, F. Zhou, and T. Xia, "Effective stress and permeability redistributions induced by successive roadway and borehole excavations," Rock Mechanics and Rock Engineering, vol. 48, no. 1, pp. 319-332, 2015.

[16] C. Karacan, R. Felicia, C. Michael, and P. Sally, "A review of capture and utilization practices with benefits to mining safety and to green-house gas reduction," International Journal of Coal Geology, vol. 86, pp. 121-156, 2011.

[17] Y. Huang and E. Wang, "Experimental study on coefficient of sensitiveness between percolation rate and effective pressure for low permeability rock," Chinese Journal of Rock Mechanics and Engineering, vol. 26, no. 2, pp. 410-414, 2007.

[18] X. Y. Jia and H. Song, "Test technology and discussion on loose zone of roadway surrounding rock," West-China Exploration Engineering, vol. 16, no. 10, pp. 148-150, 2004.

[19] F. Q. Wei, S. P. Lian, C. Zhang, and S. B. Liu, "Study on reasonable hole-sealing-depth down the seam of mengjin mine," Henan university of technology (natural science edition, vol. 32, no. 6, pp. 686-689, 2013.

[20] F. Q. Wei and S. B. Liu, "Determination and application of reasonable borehole sealing depth down seam for xinyi mine," Coal Technology, vol. 33, no. 5, pp. 46-49, 2014.

[21] B. Lin, "Theory and technology of gas prevention and control in mines," Xu Zhou, China University of Mining and Technology Press, vol. 14, no. 2, pp. 113-132, 2010.

[22] K. Zhang, K. Sun, B. Yu, and P. Ranjith, "Determination of sealing depth of in-seam boreholes for seam gas drainage based on drilling process of a drifter," Engineering Geology, vol. 210, pp. 115-123, 2016. 
[23] C. J. Fan, S. Li, M. Luo, W. Du, and Z. Yang, "Coal and gas outburst dynamic system," International Journal of Mining Science and Technology, vol. 27, no. 1, pp. 49-55, 2017.

[24] Q. Liu, C. Yuanping, Y. Liang, F. Youxiang, S. Dezhou, and K. Shengli, "A new effective method and new materials for high sealing performance of cross-measure CMM drainage boreholes," Journal of Natural Gas Science and Engineering, vol. 21, pp. 805-813, 2014.

[25] D. Zhao and J. T. Pan, "Numerical simulation on reasonable hole-sealing depth of boreholes for gas extraction," AIP Advances, vol. 8, no. 4, pp. 146-153, 2018.

[26] Q. L. Zou, H. Liu, Z. Jiang, and X. Wu, "Gas flow laws in coal subjected to hydraulic slotting and a prediction model for its permeability-enhancing effect," Energy Sources, Part A: Recovery, Utilization, and Environmental Effects, 2021.

[27] Z. Wang and J. Liu, "Problems existing in methane drainage in coal mines of China and probing into the countermeasures," Safety In Coal Mines, vol. 36, pp. 29-32, 2005.

[28] C. Wang, S. Yang, C. Jiang et al., "A method of rapid determination of gas pressure in a coal seam based on the advantages of gas spherical flow field," Journal of Natural Gas Science and Engineering, vol. 45, pp. 502-510, 2017.

[29] Q. L. Zou, H. Liu, Y. Zhang, Q. Li, J. Fu, and Q. Hu, "Rationality evaluation of production deployment of outburstprone coal mines: a case study of nantong coal mine in chongqing, China," Safety Science, vol. 122, pp. 201-221, 2020.

[30] J. B. Geng, J. Xu, W. Nie, S. Peng, C. Zhang, and X. Luo, "Regression analysis of major parameters affecting the intensity of coal and gas outbursts in laboratory," International Journal of Mining Science and Technology, vol. 27, no. 2, pp. 327-332, 2017.

[31] O. Jianchun, M. Liu, C. Zhang, Y. Liu, and J. Wei, "Determination of indices and critical values of gas parameters of the first gas outburst in a coal seam of the xieqiao mine," International Journal of Mining Science and Technology, vol. 22, no. 1, pp. 89-93, 2012.

[32] H. Jiang and Y. Luo, "Development of a roof bolter drilling control process to reduce the generation of respirable dust," International Journal of Coal Science \& Technology, vol. 8, no. 2, pp. 199-204, 2021.

[33] K. Wang, Z. Lou, G. Wei, and W. Lu, "Reasonable minimum sealing length of in-seam boreholes for coal mine methane drainage: a case study," Energy Sources, Part A: Recovery, Utilization, and Environmental Effects, vol. 42, no. 18, pp. 2199-2213, 2019.

[34] K. Wang, Z. Lou, G. Wei, B. Qin, and L. Wang, "A novel antiair-leakage method and an organic polymer material for improving methane drainage performance," Process Safety and Environmental Protection, vol. 129, pp. 152-162, 2019.

[35] H. Yu, S. Liu, Z. Liu, and H. Jia, "Macro and micro grouting process and the influence mechanism of cracks in soft coal seam," International Journal of Coal Science \& Technology (prepublish), 2021.

[36] J. He and K. Dong, "Research on rational sealing depth of gas drainage borehole in large section roadway," China Coal, vol. 4, no. 2, pp. 101-104, 2014.

[37] M. Bai, "Research and practice of reasonable hole sealing depth of the low permeability coal seam," Coal and Chemical Industry, vol. 36, no. 7, pp. 59-61, 2013.

[38] E. I. Shemyakin, G. L. Fisenko, M. V. Kurlenya et al., "Zonal disintegration of rocks around underground workings," Part II: Rock fracture simulated in equivalent materials: Soviet Mining, vol. 22, no. 3, pp. 223-232, 1986.
[39] H. Tian, G. P. Li, and A. R. Chen, "Degradation process assessment of prestressed concrete continuous bridges in lifecycle," Journal of Central South University of Technology, vol. 19, no. 5, pp. 1411-18, 2012.

[40] C. Zhai, B. Q. Lin, and L. Wang, "Status and problems of drainage and utilization of down hole coal bed methane in coal mines in China," Natural Gas Industry, vol. 28, no. 7, pp. 23-26, 2008. 